Creation and control of variably shaped plasmas in TCV

This article has been downloaded from IOPscience. Please scroll down to see the full text article.

1994 Plasma Phys. Control. Fusion 36 B277

(http://iopscience.iop.org/0741-3335/36/12B/023)

View the table of contents for this issue, or go to the journal homepage for more

Download details:

IP Address: 128.178.125.142

The article was downloaded on 18/02/2013 at 08:44

Please note that terms and conditions apply. 


\title{
Creation and Control of Variably Shaped Plasmas in TCV
}

\author{
F. Hofmann, J.B. Lister, M. Anton, S. Barry, R. Behn, S. Bernel, G. \\ Besson, F. Bühlmann, R. Chavan, M. Corboz, M.J. Dutch, B.P. Duval, \\ D. Fasel, A. Favre, S. Franke, A. Heym, A. Hirt, Ch. Hollenstein, P. \\ Isoz, B. Joye, X. Llobet, J.C. Magnin, B. Marletaz, Ph. Marmillod, Y. \\ Martin, J.M. Mayor, J.M. Moret, Ch. Nieswand, P.J. Paris, A. \\ Perez, Z.A. Pietrzyk, R.A. Pitts, A. Pochelon, R. Rage, O. Sauter, G. \\ Tonetti, M.Q. Tran, F. Troyon, D.J. Ward, H. Weisen
}

Centre de Recherches en Physique des Plasmas

Ecole Polytechnique Fédérale de Lausanne Association EURATOM-Confédération Suisse

21 Avenue des Bains, CH-1007 Lausanne, Switzerland

\begin{abstract}
During the first year of operation, the TCV tokamak has produced a large variety of plasma shapes and magnetic configurations, with $1.0 \leq \mathrm{B} \leq 1.46 \mathrm{~T}, \mathrm{I}_{\mathrm{p}} \leq 800 \mathrm{kA}, \kappa \leq 2.05,-0.7 \leq \delta \leq 0.7$. A new shape control algorithm, based on a finite element reconstruction of the plasma current in real time, has been implemented. Vertical growth rates of $800 \mathrm{sec}^{-1}$, corresponding to a stability margin $\mathrm{f}=1.15$, have been stabilized. Ohmic $\mathrm{H}$-modes, with energy confinement times reaching $80 \mathrm{~ms}$, normalized beta $\left(\beta, \mathrm{aB} / \mathrm{I}_{\mathrm{p}}\right)$ of 1.9 and $\tau_{\mathrm{E}} /$ TTER $89-\mathrm{P}$ of 2.4 have been obtained in singlenulif $X$-point deuterium discharges with the ion grad $B$ drift towards the $\mathrm{X}$-point. Limiter $\mathrm{H}$-modes with maximum line averaged electron densities of $1.7 \times 10^{20} \mathrm{~m}^{-3}$ have been observed in D-shaped plasmas with $360 \mathrm{kA} \leq I_{\mathrm{p}} \leq 600 \mathrm{kA}$.
\end{abstract}

\section{Introduction}

TCV is a compact, highly elongated tokamak, capable of producing limited or diverted plasmas with currents up to 1 MA. Since the main aim of TCV is to investigate effects of plasma shape on tokamak physics, the machine has been designed such that it can produce diverse plasma shapes without requiring hardware modifications. This versatility can easily be achieved for plasmas with moderate elongation, but for highly elongated plasmas, a close fitting passive shell becomes necessary, which is clearly in conflict with the idea of variable shape. The design of TCV can be considered as a compromise between maximum shape variability and a good passive vertical stability.

In order to satisfy these conflicting requirements, TCV incorporates a number of unusual design features: The poloidal field system consists of an $\mathrm{OH}$ transformer and sixteen independently driven shaping coils located between the vacuum vessel and the toroidal field coils. The vacuum vessel is a continuously welded structure with low toroidal resistance ( $55 \mu \mathrm{Ohms}$ ) and a nearly rectangular cross-section (height to width ratio of 3 ). First wall protection consists of high purity, isotropic graphite tiles 
covering the vessel inboard wall and floor, together with a full toroidal belt limiter mounted on the outboard wall $23 \mathrm{~cm}$ below the midplane. In addition, eight symmetrically disposed, full poloidal bands of tiles afford some protection at the top of the vessel and cover the in-vessel poloidal magnetic field probe arrays. Two fast acting coils will be installed later this year inside the vessel to stabilize rapidly growing vertical modes. Installation of an ECRH system (4.5 MW) will begin in 1995 .

TCV produced its first plasma in November 1992, with full tokamak operation starting in June 1993. During the first experimental campaign (June 1993 - November 1993), plasma breakdown and current ramp-up conditions were optimized and Dshaped plasmas with Ip $\leq 700 \mathrm{kA}, \mathrm{K} \leq 2.0$ were produced. Most of these plasmas were limited on the inner wall of the vacuum vessel. TCV operation was suspended between November 1993 and February 1994 for the installation of additional diagnostics (Thomson scattering [1], FIR interferometer [2], camera ports, etc.). The second experimental campaign was mainly devoted to the optimization of the vertical position control system and to the creation of single-null divertor configurations, suitable for ohmic $\mathrm{H}$-mode operation. The TCV vacuum vessel was boronized for the first time in May 1994 by means of a standard glow discharge in a $10 \% \mathrm{~B}_{2} \mathrm{H}_{6} / 90 \% \mathrm{He}$ gas mixture.

In this paper, section 2 briefly describes the methods used to create highly elongated and shaped plasmas, and section 3 discusses the vertical stability and the limits of plasma current and elongation imposed by our present system. In section 4 , the results on the ohmic $\mathrm{H}$-mode in TCV are presented and in section 5 , we give a preliminary analysis of energy confinement time in various types of discharges.

\section{Shape Control}

There are probably as many methods for plasma shape control as there are shaped tokamaks in the world [3-9] but they can be broadly divided into two categories. In the first are algorithms which use a large database of precalculated equilibria to obtain shape parameters from the measurements. This can be achieved in several different ways, using, for example, Singular Value Decomposition [5], Function Parametrization [8], Neural Networks [6,7], etc. In the second category are methods which determine the plasma shape without reference to a database, such as a local expansion of the flux function [3] or an approximate reconstruction of the plasma current in real time [9].

In TCV many of these methods can be tested. Here, we shall only discuss one particular algorithm [9], i.e. the one used almost exclusively by the experiments described in this paper. This algorithm is based on a finite element reconstruction of the plasma current [10], performed in real time by an analog-digital hybrid computer. The reconstructed plasma current distribution can then be used either to compute global shape parameters (e.g. radial position, vertical position, elongation, triangularity, etc.) or to calculate flux errors at the plasma boundary. In the former case, the coil currents must be essentially preprogrammed, and corrections are applied in the form of moments (radial field, vertical field, quadrupole field, etc.). The strength of these moments depends on the difference between the actual shape parameters and their preprogrammed values. In the latter case, the coil current corrections are computed such as to minimize the flux errors at the plasma boundary. This second algorithm, however, is highly non-linear since the plasma shape changes with time and the points at which the flux errors must be evaluated move together with the plasma boundary.

To date, the moments method has been found to be sufficient for the relatively uncomplicated plasma shapes explored. Figure 1 shows pre-programmed and 


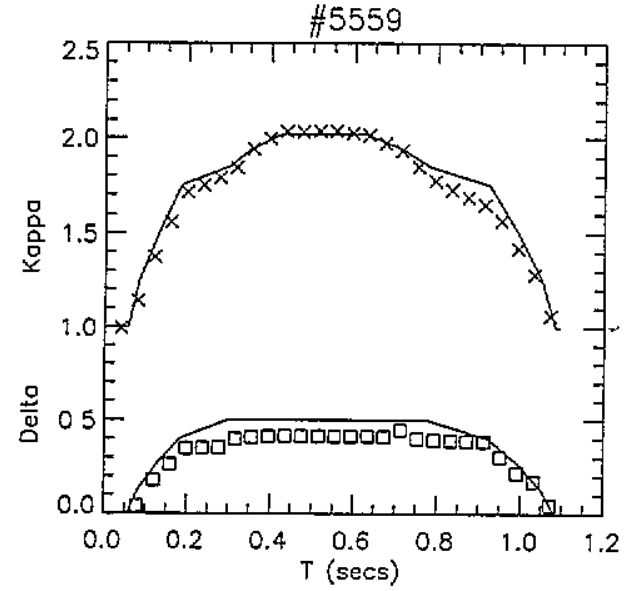

Figure 1. (a) Preprogrammed (lines) and measured (symbols) shape parameters for limiter discharge with $I p(\max )=810 \mathrm{kA}$

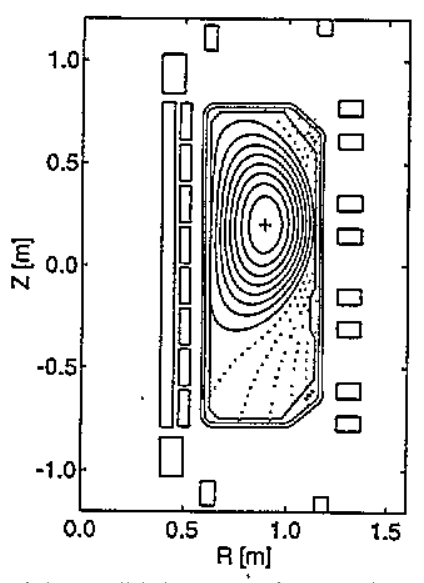

(b) Magnetic configuration at $\mathrm{t}=0.5 \mathrm{sec}$.
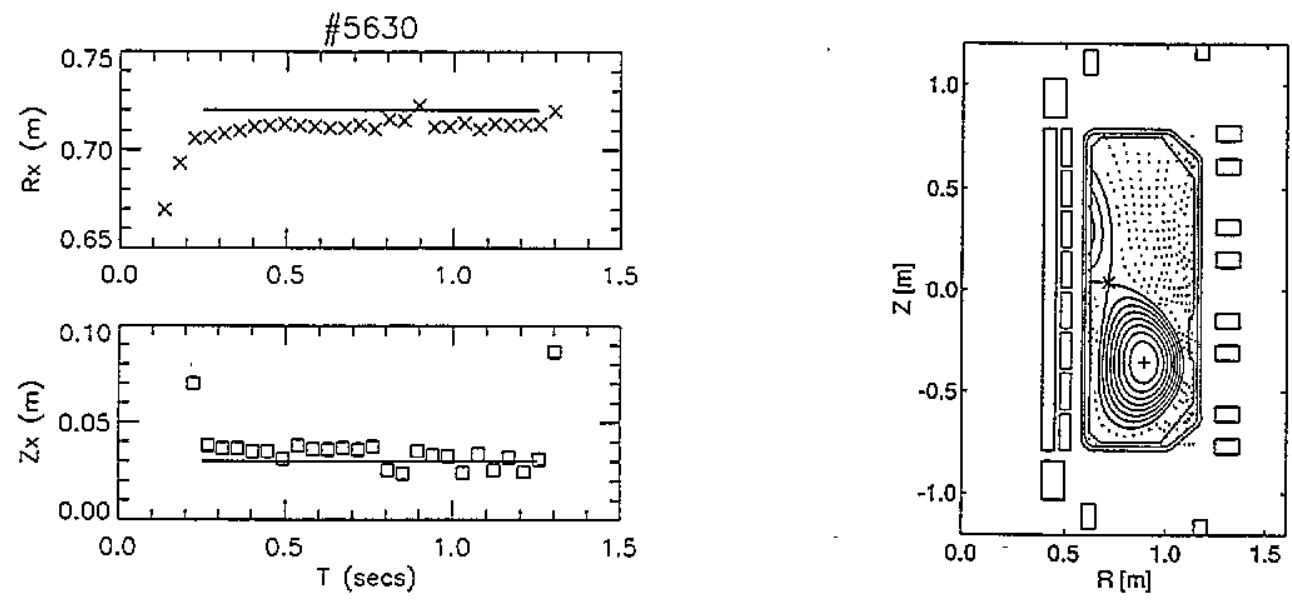

Figure 2. (a) Preprogrammed (lines) and measured (symbols) $X$-point coordinates for SNX discharge with $\mathrm{Ip}(\max )=330 \mathrm{kA}$

(b) Magnetic configuration at $\mathrm{t}=0.5 \mathrm{sec}$.

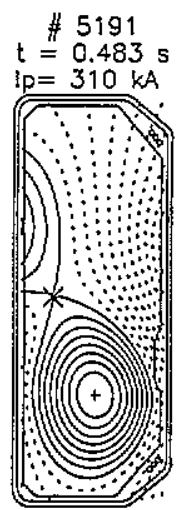

(a)

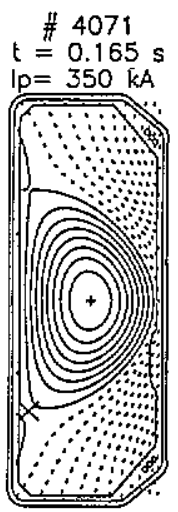

(b)

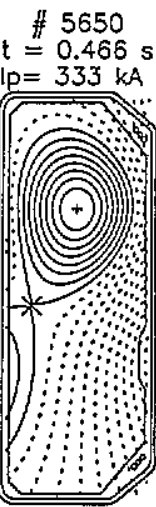

(c)

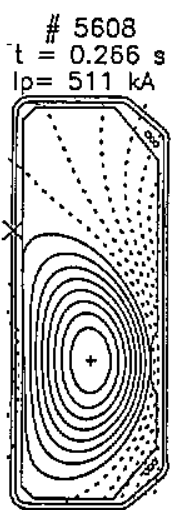

(d)

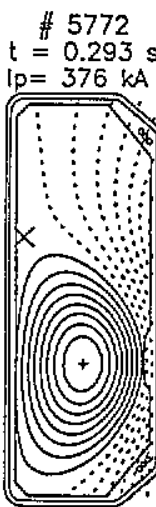

(e)

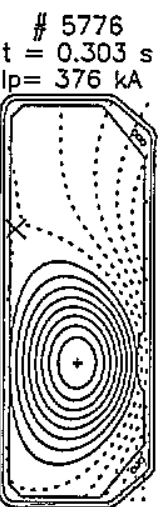

(f)
\# 4211

$\mathrm{t}=0.433 \mathrm{~s}$

$1 p=216 \mathrm{kA}$

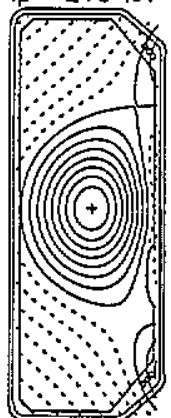

(g)

Figure 3. Various plasma shapes produced in TCV 
measured shape parameters for a typical limiter discharge. The measured shape parameters were obtained from a full equilibrium reconstruction [11], performed after the discharge. In a second example, figure 2 compares the preprogrammed and measured $\mathrm{X}$-point coordinates of a typical diverted plasma. The shape control algorithm has been tested on a large variety of different configurations. Figures $3 a-3 g$ show a selection of equilibrium reconstructions of plasmas that have been produced in TCV.

\section{Vertical Stability}

One of the aims of TCV is to produce plasmas with very high elongation $(\kappa \leq 3)$ which are highly unstable with respect to $n=0$ modes. These modes have been studied by many authors [12-17], and calculations for TCV $[16,17]$ have been performed with the NOVA-W code [18], which includes effects of passive and active feedback elements, as well as plasma deformability. Figure 4 shows some typical results of such calculations with the open-loop growth rate of D-shaped plasmas in TCV shown as a function of elongation ( $\kappa$ ). For $\kappa=2$, the equilibrium parameters are those obtained experimentally and for higher values of $\kappa$, the plasma current is assumed to increase linearly with elongation and $\mathrm{q}_{0}$ and $\beta_{\mathrm{p}}$ to remain constant. In addition, the plasma vertical position is adjusted such that the minimum distance between the plasma boundary and the vacuum vessel floor remains constant. The growth rate saturates above $\kappa=2.9$, due to the additional stabilization from the top wall. A comparison between theoretical and experimental growth rates for a plasma with $I_{p}=260 \mathrm{kA}, K=1.6$, $\delta=0.2$ and $Z_{0}=-0.23 \mathrm{~m}$ shows agreement to within $20 \%$.

TCV is equipped with sixteen shaping coils driven independently by thyristor controlled power supplies with a response time of the order of $1 \mathrm{~ms}$. Any combination of shaping coils can be used for vertical position control. However, if the growth rates of highly elongated TCV plasmas (figure 4) are compared with the response time of the shaping power supplies, it is clear that the plasmas with maximum elongation cannot be stabilized using the shaping coils alone. Therefore, it is planned to install a set of internal coils driven by a fast power supply, with a response time of the order of $0.1 \mathrm{~ms}$. Theoretical calculations [16] show that using these fast coils, in combination with the slower shaping coils, should allow the stabilization of growth rates of the order of $2500 \mathrm{sec}^{-1}$.

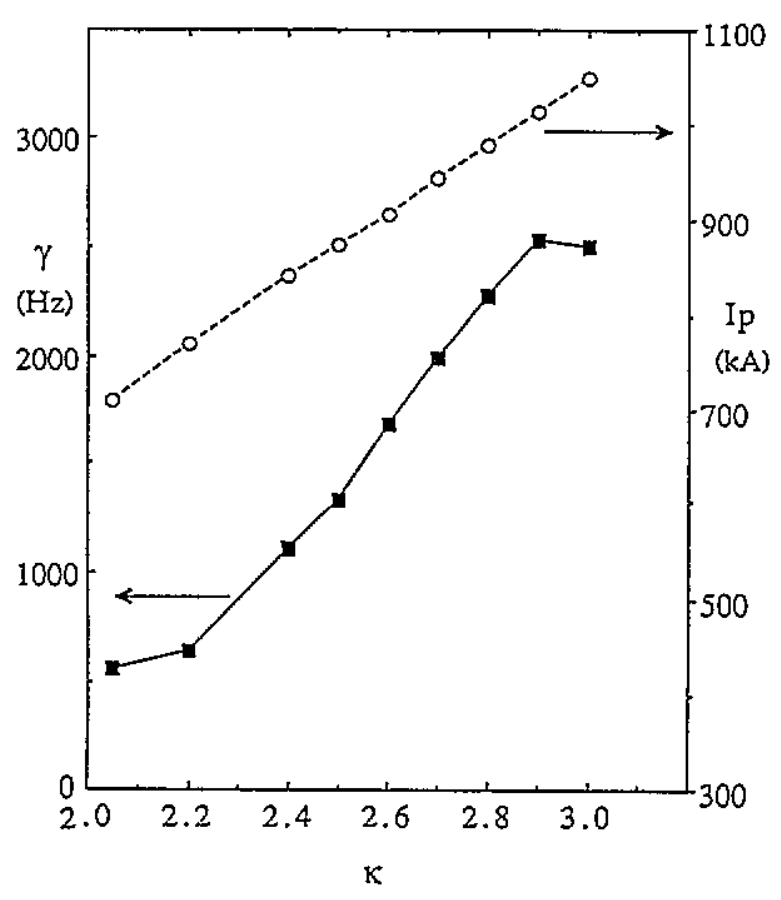

Figure 4. Theoretical growth rate of vertical instability $(\gamma)$ and plasma current $\left(I_{p}\right)$ vs. elongation for D-shaped plasmas in TCV. 
Several experiments have been performed on TCV to determine the maximum vertical growth rate that can be stabilized with the present system. No definitive value has yet been obtained since there are many different ways to measure vertical position and to configure the feedback system, and the optimum choice depends on the plasma configuration being considered. In one particular set of experiments, using four outboard coils for vertical position and velocity control, open-loop growth rates up to $\gamma=800 \mathrm{sec}^{-1}$ were stabilized for elliptical plasmas. Since the $\mathrm{m}=1$ shell time, $\gamma_{s}^{-1}$, is $8.2 \mathrm{~ms}$ in TCV, this corresponds to a stability margin, $\mathrm{f}=\left(\gamma_{\mathrm{s}} / \gamma\right)+1=1.15$. This is not a particularly low value since other machines have operated with much lower values of $f$ [15]. However, the open-loop growth rate in our experiments $\left(800 \mathrm{sec}^{-1}\right)$ is close to the inverse response time of the power supplies, so we are probably not far from the limit of what is presently possible in TCV. From the theoretical results in figure 4, the present restriction on the vertical growth rate imposes a limit on the attainable elongation and plasma current.

\section{Ohmic H-Mode}

Before boronization of the TCV vacuum vessel, experiments with a single null Xpoint were performed to investigate whether an $\mathrm{H}$-mode could be achieved in deuterium discharges. Since other experiments [19-22] have shown that an ohmic Hmode has a small operational parameter space, the initial experiments were designed to optimize a possible $\mathrm{H}$-mode transition. The $\mathrm{X}$-point was placed near the inner midpoint of the TCV vessel with a distance of more than $2.5 \mathrm{~cm}$ between the last closed flux surface and the graphite tiles of the inner wall and the outer belt limiter (figure 3a). The field directions were chosen such that the ion grad B drift was towards the X-point, which was previously found to be more favorable [23]. In order to maximize the ohmic power input, the nominal toroidal field (1.4T) was chosen with a $310 \mathrm{kA}$ plasma current and a modest elongation, $\kappa_{95}=1.5$, which corresponds to a safety factor $\mathrm{q}_{95}=2.3$.

During these initial experiments, distinct evidence of an $\mathrm{H}$-mode type transition was noted in several discharges - a sharp drop in the divertor $\mathrm{D}_{\alpha}$ signal coincident with a drop in the plasma loop volts and a slight increase in global energy confinement. These features were often triggered by a double sawtooth and appeared both during current ramp-up and plateau phases at a relatively constant line averaged plasma density of $<\mathrm{n}>=4 \times 10^{19} \mathrm{~m}^{-3}$. In the short period between these preliminary observations and the first boronization of TCV, diverted discharges with magnetic configurations shown in figures $3 \mathrm{a}$ and $2 \mathrm{~b}$ showed no further $\mathrm{H}$-mode activity. These experiments were accompanied by a continuous increase in the divertor $D_{\alpha}$ signals and hence edge recycling, which appeared to prevent the $\mathrm{H}$-mode transition.

Following boronization, some $\mathrm{H}$-mode activity was again observed and, after a 30 min glow in Helium, sustained ohmic H-modes lasting up to $1 \mathrm{sec}$ were obtained with the configuration shown in figure $2 \mathrm{~b}$. In these discharges (figures 5 and 6), there was clear evidence of a density threshold for the $\mathrm{H}$-mode transition. As the plasma density was increased, there was often a short dithering period, followed by the H-mode transition and an ELM-free period. In discharges where large ELMs halted the density rise, and the gas puff was moderate, transition from $\mathrm{H}$ back to $\mathrm{L}$ mode was achieved without a disruption (figure 5). In cases where no ELMs were observed, the discharge terminated with a high density disruption (figure 6). The maximum line-averaged electron density measured in ELM-free $\mathrm{H}$-modes (configuration figure $2 \mathrm{~b}$ ) was $1.5 \times 10^{20} \mathrm{~m}^{-3}$, corresponding to $80 \%$ of the Greenwald limit, $\left\langle\mathrm{n}_{\mathrm{e}}\right\rangle_{\mathrm{GL}}=0.27 \mathrm{I}_{\mathrm{p}} / \mathrm{a}^{2}[24]$. 


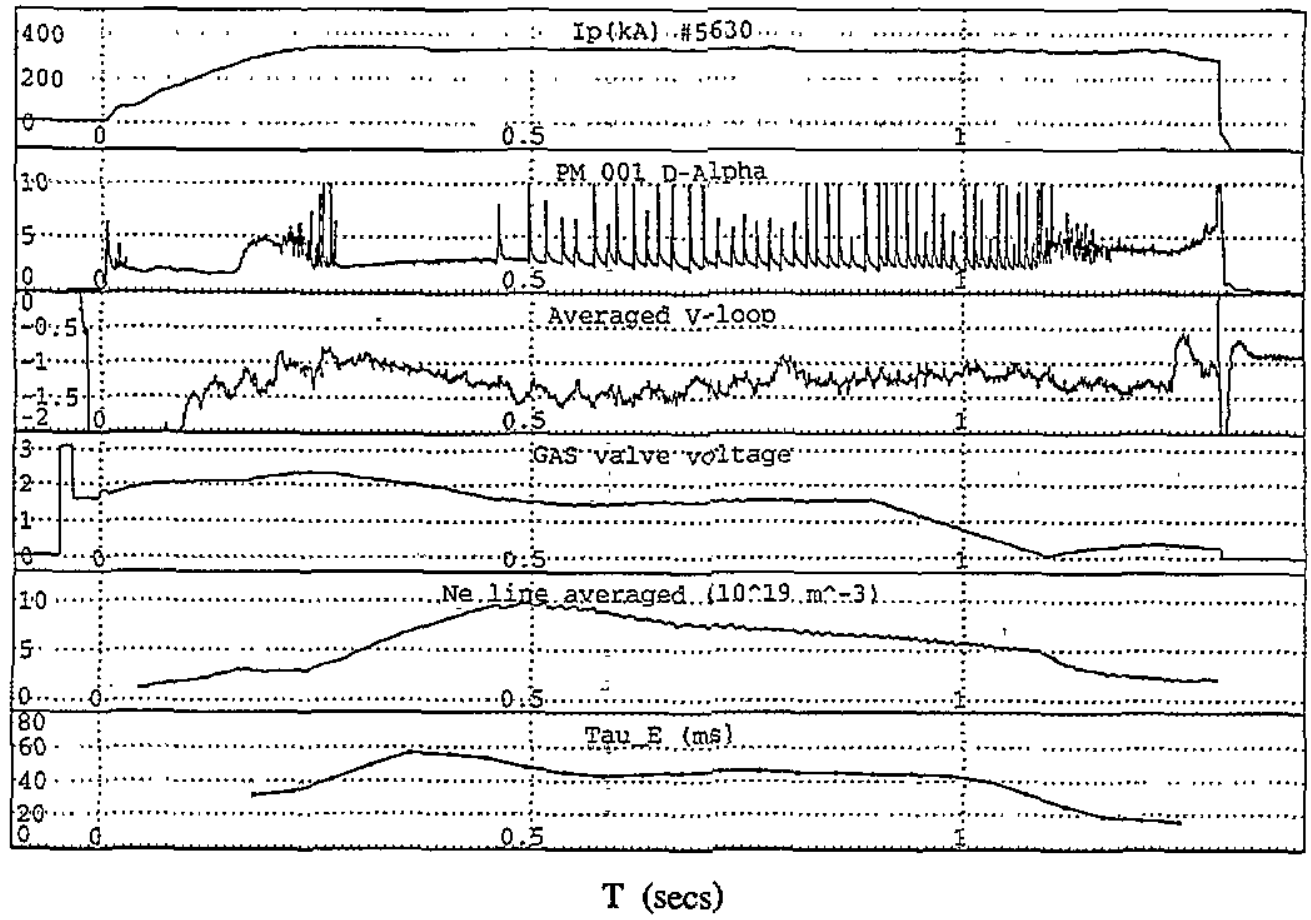

Figure 5. ELMy H-mode discharge (configuration figure 2b)

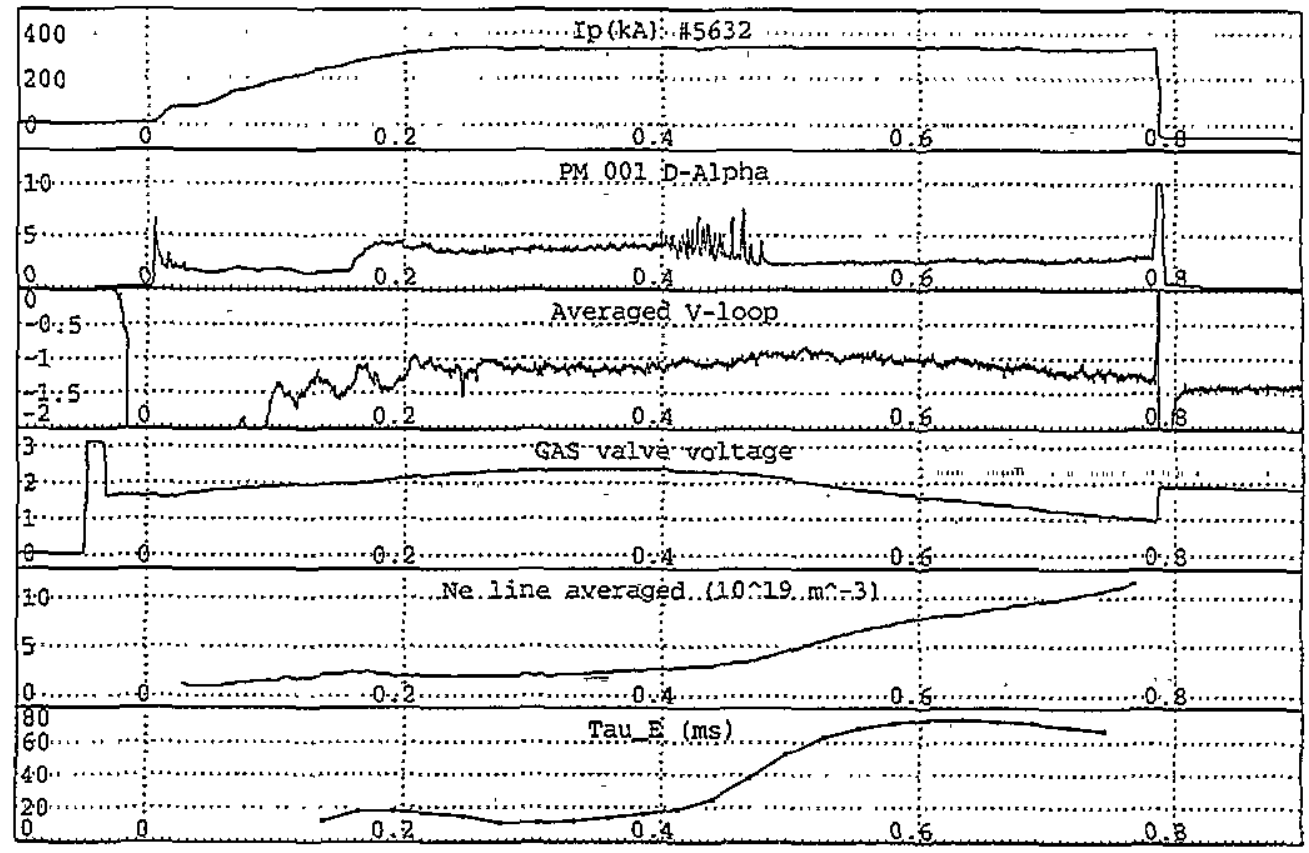

\section{$\mathrm{T}$ (secs)}

Figure 6. ELM-free H-mode with late L-H transition due to low initial density. 
In order to determine the power threshold for the $\mathrm{H}$-mode transition, a plasma current scan was performed with the magnetic configuration shown in figure $2 b$, at constant toroidal magnetic field, corresponding to a scan of $q_{95}$ from 2.1 at $340 \mathrm{kA}$ to 3.2 at $210 \mathrm{kA}$. Previous results have shown the required ohmic $\mathrm{H}$-transition power per unit plasma surface area to scale with the product of toroidal field and line averaged plasma density [19]. The current scan gave a threshold for $\mathrm{H}$-mode between 210kA and $240 \mathrm{kA}$, which when compared with other machines [19-22] shows that TCV has easy access to the $\mathrm{H}$-regime with relatively low input power. The $\mathrm{H}$-transition was indeed found to occur at a relatively constant plasma density for each plasma current, which is well demonstrated in figure 5. Here, the initial L-H transition occurs at the same density as the final H-L transition, when the density drops below the critical value of $4 \times 10^{19} \mathrm{~m}^{-3}$. We also observed in these experiments that the critical density for the L-H transition is slightly higher when the transition occurs late in the discharge.

To investigate the importance of the ion drift direction, the configuration shown in figure $2 \mathrm{~b}$ was inverted, maintaining the direction of $\mathrm{B}_{\text {tor }}$ (figure $3 \mathrm{c}$ ). Operation with a plasma current of $330 \mathrm{kA}$ indeed showed some evidence of an $\mathrm{H}$-mode transition at a plasma density very similar to that for the transition observed in the original configuration (figure $2 \mathrm{~b}$ ) at this current. In this case, the density rise following the transition saturated before there was clear ELM activity. Since a further He glow did not improve this $\mathrm{H}$-mode, we conclude that the power threshold in the configuration with the ion grad B drift away from the X-point is at least $50 \%$ higher than with the ion drift towards the X-point.

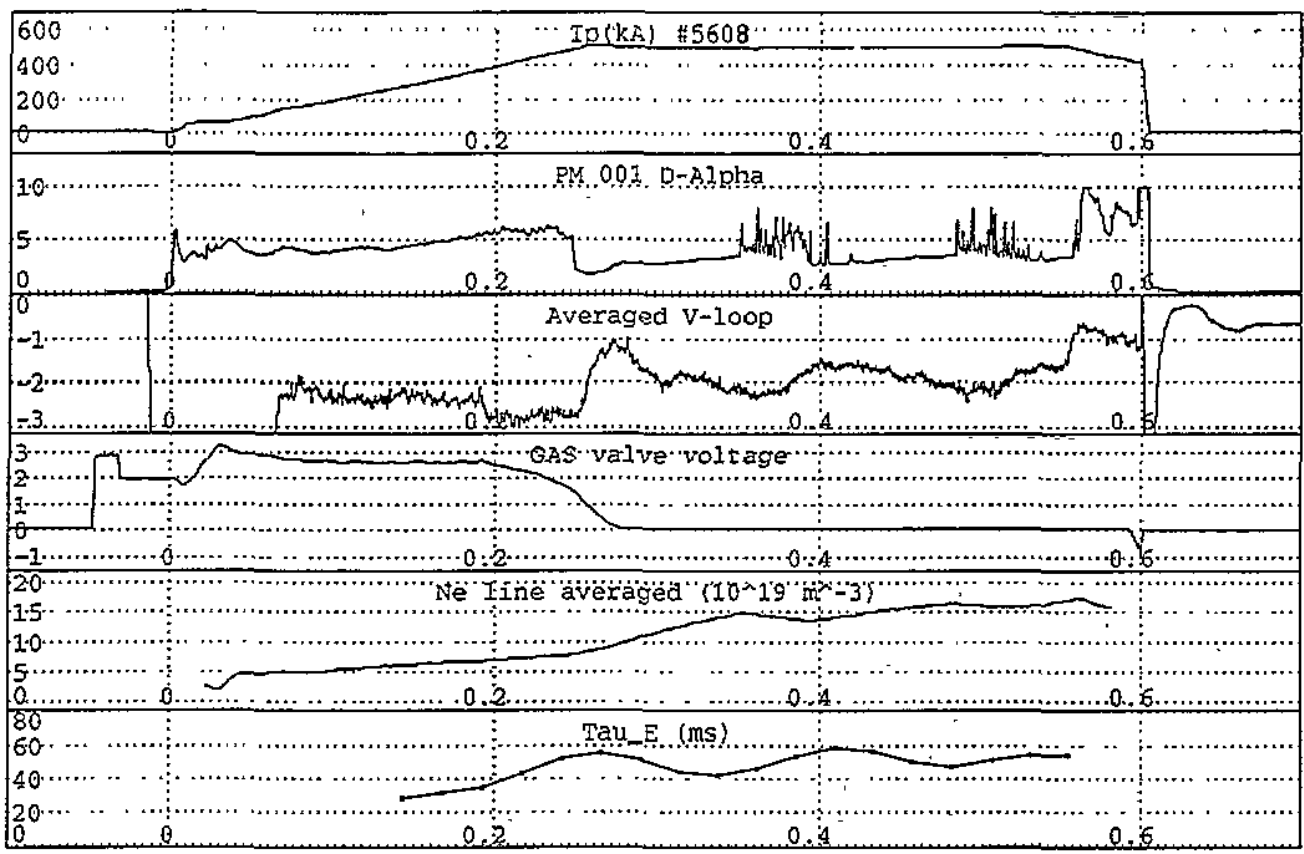

$T(\operatorname{secs})$

Figure 7. $\mathrm{H}$-mode in D-shaped limiter plasma (configuration figure 3d) 
The density limit, following boronization of the vessel, is often used as a measure of the "quality" of the wall boronization. Although little deterioration was observed in the density limit, measured from the high density disruptions during ELM free operation, it became impossible to avoid long ELM-free discharges which inevitably terminated with a density disruption. A 30min Helium glow immediately restored the large ELM activity, stabilizing the density rise during the H-mode phase.

The importance of high density for the ohmic H-mode in TCV was unexpectedly demonstrated in a series of limiter discharges with high elongation $(\kappa=1.9)$ and plasma currents up to $600 \mathrm{kA}$ (e.g. figure $3 \mathrm{~d}$ with $\mathrm{Ip}=510 \mathrm{kA}$ ). As the density was raised by gas puffing, the discharge went into $\mathbf{H}$-mode at fairly reproducible plasma density $\left(<n_{e}>=8 \times 10^{19} \mathrm{~m}^{-3}\right)$ and there were ELM-free and large ELM periods (figure 7). The maximum line averaged electron density reached in these limiter discharges was $1.7 \times 10^{20} \mathrm{~m}^{-3}$ and although some discharges showed several L-H and $\mathrm{H}-\mathrm{L}$ transitions, all terminated in a major disruption. The magnetic configuration was nearly up-down symmetric with two $X$-points located close to the vessel wall (figure $3 \mathrm{~d}$ ). The distance between the $X$-points and the plasma boundary was $9 \mathrm{~cm}$ and the poloidal flux difference between the $X$-point and the limiter surface was $4 \%$ of the total poloidal flux within the plasma. This leads to an extremely wide interaction zone of the scrape off layer with the carbon tiles, which may explain the access to a limiter $\mathrm{H}$-mode in TCV.

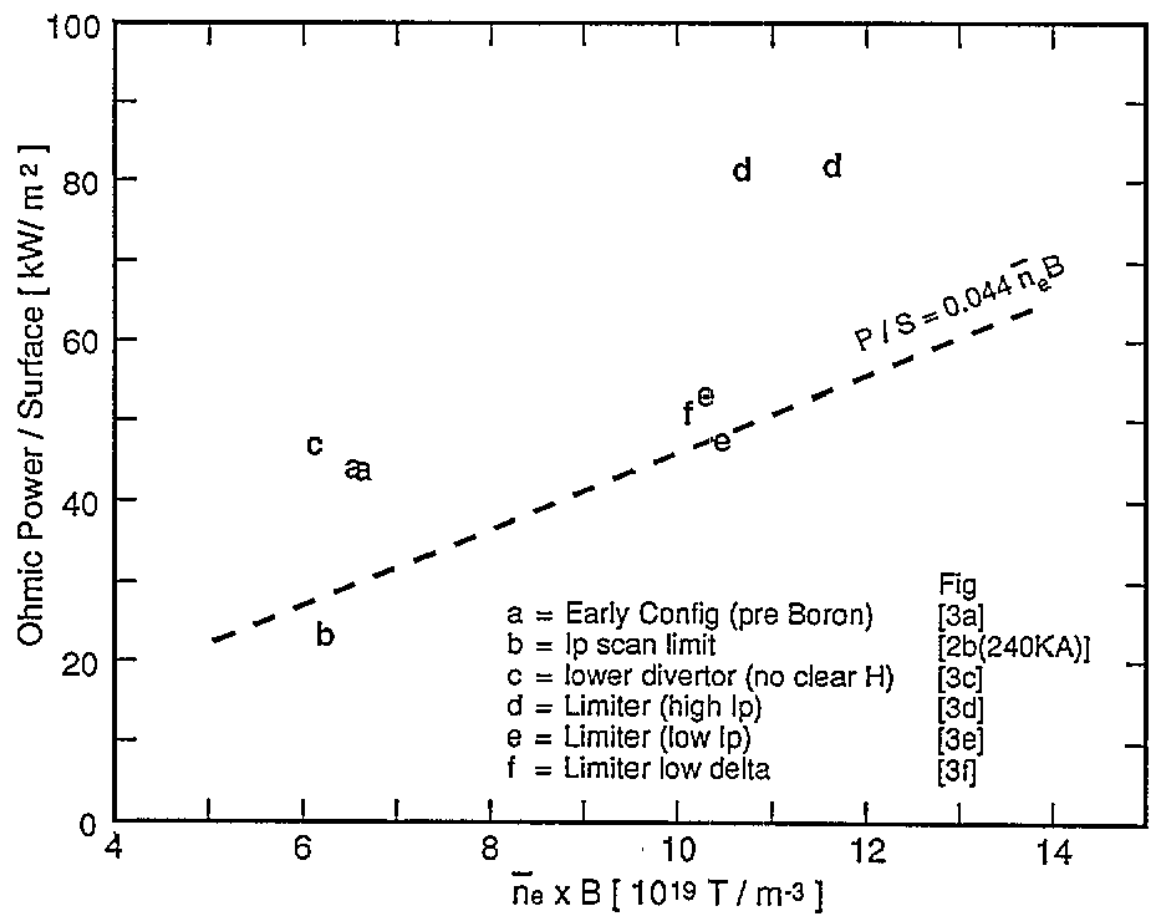

Figure 8. Ohmic power divided by the area of the last closed flux surface vs. $n_{e} B$ for L-H transitions in TCV. Dashed line is scaling from Ref. [19].

In these experiments the power threshold for the limiter $\mathrm{H}$-mode depended on the plasma triangularity. A discharge with $I_{p}=370 \mathrm{kA}, \kappa=1.7, \delta=0.4$ (figure $3 \mathrm{e}$ ) showed reproducible $\mathrm{L}-\mathrm{H}$ transitions at line-averaged densities around $7 \times 10^{19} \mathrm{~m}^{-3}$. When the triangularity was decreased to $\delta=0.25$ (figure $3 f$ ), the transition no longer occurred, but 
with a slightly larger plasma current, $I_{p}=400 \mathrm{kA}$, the limiter $\mathrm{H}$-mode reappeared. This may be explained by the fact that the distance between the $X$-point and the plasma boundary increases with decreasing triangularity. In figure $3 \mathrm{f}$, this distance is quite large $(17 \mathrm{~cm})$, and the flux between the X-point and the limiter surface amounts to $12 \%$ of the total plasma flux. Yet, this configuration (with $\mathrm{I}_{\mathrm{p}}=400 \mathrm{kA}$ ) showed a clear L-H transition at $\left\langle\mathrm{n}_{\mathrm{e}}\right\rangle=7.2 \times 10^{19} \mathrm{~m}^{-3}$. A summary of the threshold conditions for the ohmic H-mode in TCV is shown in figure 8 and compared with the scaling law given in Ref. [19].

\section{Energy Confinement Time}

In this section, we present a preliminary analysis of the energy confinement time in $\mathrm{L}$ and $\mathrm{H}$-mode discharges. Since electron density and temperature profiles are only available for a small fraction of the discharges [1] and ion temperatures are not yet measured, $\tau_{F}$ is derived from equilibrium reconstructions [11], based on magnetic measurements. The energy confinement time is calculated as $\tau_{\mathrm{F}}=\mathrm{W} /\left(\mathrm{I}_{\mathrm{P}} \mathrm{V}_{1}-\mathrm{dW} / \mathrm{dt}-\right.$ $\mathrm{dU} / \mathrm{dt})$, where $\mathrm{W}$ is the plasma thermal energy, $\mathrm{W}=(3 / 2) \int \mathrm{pdV}, \mathrm{V}_{1}$ is the loop voltage evaluated on the last closed flux surface, and $U$ is the internal poloidal magnetic field energy, $U=\left(\mu_{0} / 4\right) I_{i} R_{0} I_{p}{ }^{2}$.

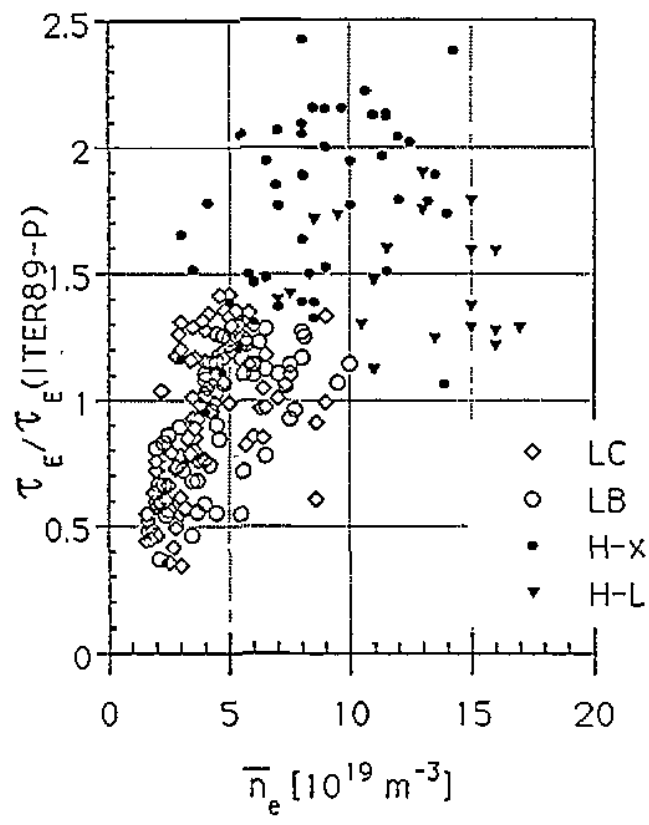

(a)

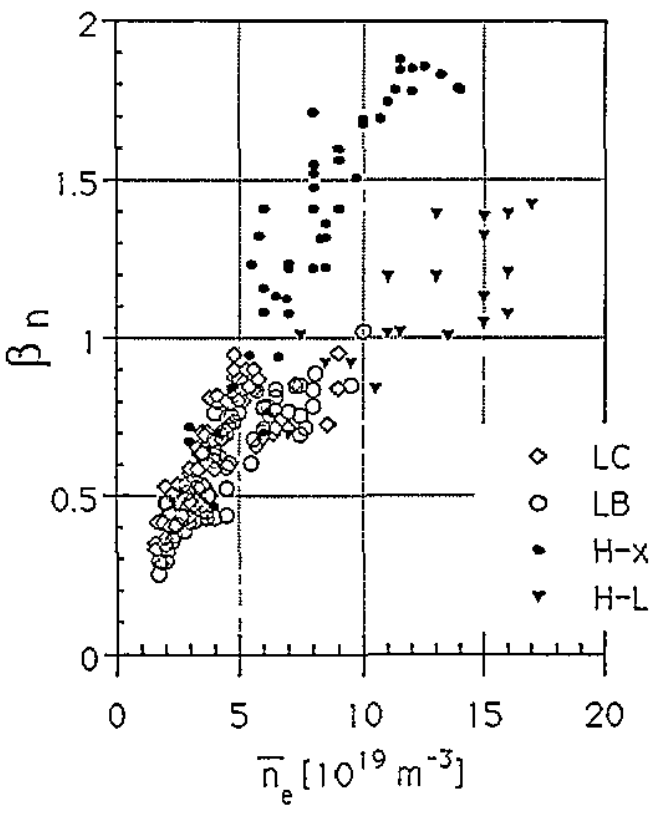

(b)

Figure 9. Enhancement of energy confinement time with respect to ITER89-P (a) and normalized beta (b) vs. line averaged electron density, for L-mode discharges in unboronized (LC) and boronized vessel (LB) and for H-mode discharges with singlenull $\mathrm{X}$-point $(\mathrm{H}-\mathrm{X})$ and limiter configuration $(\mathrm{H}-\mathrm{L})$. 
In figure 9a, the enhancement of the energy confinement time with respect to ITER 89-P scaling is shown as a function of line averaged electron density for four different types of discharges. The plot includes plasmas within the following parameter ranges: $250 \mathrm{kA}<\mathrm{I}_{\mathrm{p}}<800 \mathrm{kA}, 1.2<\kappa<2.05,0.1<\delta<0.5,2.1<\mathrm{q}_{95}<4.5$, and $1.0<\mathrm{B}_{\text {tor }}<1.46 \mathrm{~T}$. The TCV database is currently too sparse to provide a definite dependence of $\tau_{E}$ on plasma shape and current. In $L$-mode, the maximum enhancement in $\tau_{E}$ increases until $<n>\sim 5 \times 10^{19} \mathrm{~m}^{-3}$ and stays at this value for higher $<n>$. This dependence did not change significantly with boronization. In contrast, for $\mathrm{H}$-modes with a single-null $\mathrm{X}$ point configuration, the enhancement in $\tau_{E}$ increases up to $<n>\sim 1 \times 10^{20} \mathrm{~m}^{-3}$ and then decreases. The maximum energy confinement time obtained in an ELM-free H-mode was $80 \mathrm{~ms}$, corresponding to an enhancement factor of 2.4 . In limiter $\mathbf{H}$-modes, the enhancement in $\tau_{E}$ also increases with $\left\langle\mathrm{n}_{\mathrm{e}}\right\rangle$, but the values are considerably lower than in divertor configurations. Figure $9 \mathrm{~b}$ shows a plot of normalized beta, $\beta_{\mathrm{N}}=\left(\beta_{\text {tor }}[\%] \mathrm{a}[\mathrm{m}] \mathrm{B}[\mathrm{T}] / \mathrm{I}_{\mathrm{p}}[\mathrm{MA}]\right)$. The $\mathrm{H}$-modes reach much higher $\beta_{\mathrm{N}^{-v}}$ alues than $\mathrm{L}$ modes, and the maximum values obtained in single-null $X$-point configurations are about a factor of 1.4 above those observed in limiter $\mathrm{H}$-modes.

\section{Conclusion}

Using a novel shape control algorithm [9], TCV has produced plasmas with various shapes and magnetic configurations, characterized by $1.0 \leq \mathrm{B}, \leq 1.46 \mathrm{~T}, \mathrm{I}_{\mathrm{p}} \leq 800 \mathrm{kA}$, $\kappa \leq 2.05, \delta \leq 0.7$. The optimization of the vertical position control system has allowed the stabilization of vertical growth rates up to $800 \mathrm{sec}^{-1}$, which is close to the inverse of the response time of the power supplies.

Experiments with a single-null $X$-point and plasma currents between $210 \mathrm{kA}$ and $340 \mathrm{kA}$ showed that TCV has easy access to the ohmic H-mode if the ion grad B drift is directed towards the X-point, and if the vessel is boronized and conditioned with helium glow discharges. ELMy and ELM-free H-modes, lasting for $1.0 \mathrm{sec}$ and $0.4 \mathrm{sec}$, respectively, have been obtained. Energy confinement times of $80 \mathrm{~ms}$, normalized beta $\left(\beta_{\mathrm{tar}} \mathrm{aB} / \mathrm{T}_{\mathrm{p}}\right)$ of 1.9 and $\tau_{\mathrm{E}}$ enhancement $\left(\tau_{\mathrm{E}} /\right.$ ITER $\left.89-\mathrm{P}\right)$ of 2.4 have been observed in ELM-free ohmic H-modes. The L-H transition is observed to occur at a constant density for each combination of plasma current and magnetic configuration. Reversing the direction of the ion grad B drift prevented the appearance of the ohmic H-mode, even with an input power corresponding to $150 \%$ of the threshold power observed in the original configuration.

Limiter $\mathrm{H}$-modes have been obtained in D-shaped plasmas with $360 \mathrm{kA} \leq \mathrm{I}_{\mathrm{p}} \leq 600 \mathrm{kA}$, $1.7 \leq \kappa \leq 1.9$. The density threshold for the limiter $\mathrm{H}$-mode transition is considerably higher than that found in the single-null $X$-point configuration, and the power threshold is found to increase with decreasing triangularity.

\section{Acknowledgements}

It is a pleasure to acknowledge the support of the TCV technical teams throughout the first experimental campaigns. This work was partially supported by the $S$ wiss National Science Foundation. 


\section{References}

[1] Behn, R., Pietrzyk, Z.A., Franke, S, this Conference.

[2] Nieswand, C., Behn, R., Bühlmann, F., et al., this Conference.

[3] O'Brien, D.P., Ellis, J.J., Lingertat, J., Nuclear Fusion 33 (1993) 467.

[4] Campbell, G.L., Ferron, J.R., McKee, E., et al. FUSION TECHNOLOGY 1992, Elsevier Science Publishers 2 (1993) 1017.

[5] Bell, R.E., Asakura, N., Bernabei, S., et al. Phys. Fluids B 2 (1990) 1271.

[6] Todd, T.N., and COMPASS Team, Plasma Phys. and Controlled Fusion 35 (1993)

[7] Lister, J.B., Schnurrenberger, H., Nuclear Fusion 31 (1991) 1291.

[8] McCarthy, P.J., Schneider, W., et al., Proc. 19th EPS Conf. on Controlled Fusion and Plasma Physics, 16C, I, 459.

[9] Hofmann, F., Jardin, S.C., Nuclear Fusion 30 (1990) 2013.

[10] Hofmann, F., Tonetti, G., Nuclear Fusion 28 (1988) 519.

[11] Hofmann, F., Tonetti, G., Nuclear Fusion 28 (1988) 1871.

[12] Perrone, M.R., Wesson, J.A., Nuclear Fusion 21 (1981) 871.

[13] Ward, D.J., Jardin, S.C., Nuclear Fusion 32 (1992) 973.

[14] Hutchinson, I.H., Nuclear Fusion 29 (1989) 2107.

[15] Lister, J.B., Lazarus, E.A., Kellman, A.G., et al. Nuclear Fusion 30 (1990) 2349.

[16] Ward, D.J., Hofmann, F., Nuclear Fusion 34 (1994) 401.

[17] Ward, D.J., Bondeson, A., Hofmann, F., Nuclear Fusion 33 (1993) 821.

[18] Ward, D.J., Jardin, S.C., and Cheng, C.Z., J. Comput. Phys. 104 (1993) 221.

[19] Ryter, F., Gruber, O., Büchl, K., et al., in Controlled Fusion and Plasma Physics (Proc.. 20th Eur. Conf. Lisboa, 1993), Vol 17C, Part I, European Physical Society (1993) I-23.

[20] Osborne, T.H., Brooks, N.H., Burrel, K.H., et al., Nuclear Fusion 30 (1990) 2023.

[21] Snipes, J.A., Granetz, R.S., Greenwald, M., submitted for publication in Nuclear Fusion.

[22] Carolan, P.G., Fielding, S.J., Gerasimov, S., et al, to be published in Plasma Physics and Controlled Fusion.

[23] ASDEX Team, Nuclear Fusion 29 (1989) 1959.

[24] Greenwald, M., et al. PFC/JA-86-22, Plasma Fusion Center, MIT, Cambridge, Mass., U.S.A. 